\title{
Clinically Nonfunctioning Pituitary Tumors Are Monoclonal in Origin
}

\author{
Joseph M. Alexander, Beverly M. K. Biller, Helen Bikkal, Nicholas T. Zervas, * Andrew Amold, and Anne Klibanski
}

Divisions of Medicine and *Neurosurgery, Massachusetts General Hospital, Boston, Massachusetts 02114

\begin{abstract}
Clinically nonfunctioning pituitary adenomas are benign neoplasms comprising $\sim 25-30 \%$ of pituitary tumors. Little is known about the pathogenesis of pituitary neoplasia. Clonal analysis allows one to make the important distinction between a polyclonal proliferation in response to a stimulatory factor versus a monoclonal expansion of a genetically aberrant cell. We investigated the clonal origin of pituitary tumors using $\mathrm{X}$-linked restriction fragment length polymorphisms at the phosphoglycerate kinase and hypoxanthine phosphoribosyltransferase genes. Restriction enzymes were used to distinguish maternal and paternal X-chromosomes, and combined with a methylation-sensitive restriction enzyme to analyze allelic $\mathrm{X}$-inactivation patterns in six pituitary adenomas. All six tumors showed a monoclonal pattern of $\mathrm{X}$-inactivation. These data indicate that nonfunctioning pituitary adenomas are unicellular in origin, a result consistent with the hypothesis that this tumor type is due to somatic mutation. (J. Clin. Invest. 1990. 86:336-340.) Key words: clonality $-X$-inactivation • phosphoglycerate kinase $\bullet$ hypoxanthine phosphoribosyltransferase • adenoma
\end{abstract}

\section{Introduction}

Clinically nonfunctioning pituitary tumors represent $25-30 \%$ of diagnosed pituitary adenomas, and often secrete glycoprotein hormones and/or their free subunits (1). These tumors are diagnosed as "nonfunctioning" because patients present with none of the classic clinical hormone excess syndromes such as acromegaly or Cushing's disease. Instead, patients present with symptoms of mass effect, including visual abnormalities, headaches, and pituitary hormone deficiencies. Transsphenoidal surgery is the primary therapeutic intervention in the majority of patients. Advances in radioimmunoassay techniques for intact pituitary glycoprotein hormones and their subunits have demonstrated that many such tumors secrete follicle-stimulating hormone (FSH), free alpha- and beta-hormone subunits, or, less commonly, intact luteinizing hormone (LH) (2-4). Light and electron microscopy studies show the presence of secretory granules in neoplastic pituitary tissue (5). RNA anal-

Address reprint requests to Dr. Anne Klibanski, Neuroendocrine Unit, Bulfinch B, Massachusetts General Hospital, Boston, MA 02114. Received for publication 9 March 1990.

J. Clin. Invest.

(c) The American Society for Clinical Investigation, Inc. 0021-9738/90/07/0336/05 \$2.00

Volume 86, July 1990, 336-340 ysis (6-9) and immunocytochemistry (10-12) also confirm the synthesis and secretion of intact gonadotropins or their subunits by a subset of nonfunctioning pituitary adenomas.

The pathogenesis of these tumors is unknown. Clonal analysis allows one to make the important distinction between a polyclonal proliferation in response to a stimulatory factor versus a monoclonal expansion of a genetically aberrant cell. Development of pituitary tumors may be due to hypothalamic dysregulation, or other factors that act to stimulate excessive cell growth in the pituitary (13). A second hypothesis favors de novo neoplastic transformation of pituitary cells due to somatic mutation of a single progenitor cell as a primary pathogenetic mechanism. Studies examining the clonal composition of tumor tissues have been important in establishing the cellular origins of many human neoplasms (14). Tumors such as neurofibromas (15) and rare hereditable trichoepitheliomas (16) have been shown to be polyclonal, indicating that factors other than somatic mutation may have contributed to their growth.

Recently, molecular biology techniques that detect restriction fragment length polymorphisms (RFLPs) ${ }^{1}$ and allelic Xinactivation patterns have demonstrated the monoclonal origins of several other tumor types, such as nonfamilial primary parathyroid adenomas (17), certain hematopoietic tumors (18), and colorectal carcinomas (19). X-inactivation patterns from normal polyclonal tissue used as control DNA were compared with tumor DNA to assess the clonal origins of each of these tumor types. To investigate the pathogenesis of pituitary tumors, we used RFLP and methylation analysis of the phosphoglycerate kinase (PGK) and hypoxanthine phosphoribosyltransferase (HPRT) genes to compare $\mathrm{X}$-inactivation patterns from patients' control blood leukocytes with that from their nonfunctioning pituitary tumors.

\section{Methods}

Nonfunctioning pituitary adenomas were obtained during transsphenoidal surgery and frozen in liquid nitrogen. Blood leukocytes from female patients were collected and patients heterozygous for either the PGK or HPRT genes were identified. Blood samples and pituitary tumor tissue were obtained as approved by the Subcommittee on Human Studies at Massachusetts General Hospital. Genomic DNA was purified from both tissues by SDS-proteinase $K$ digestion and phenol-chloroform extraction $(20,21)$. Experimental techniques for

1. Abbreviations used in this paper: HPRT, hypoxanthine phosphoribosyltransferase; MEN-1, multiple endocrine neoplasma type 1; PGK, phosphoglycerate kinase; RFLP, restriction fragment length polymorphism; TAE, Tris-Acetate-EDTA. 
clonal analysis using the PGK and HPRT loci have been previously described $(22,23)$.

Blood leukocyte DNA samples were screened for heterozygosity at the PGK and HPRT genes. $10 \mu \mathrm{g}$ of genomic DNA was incubated with Bg1 I or Bam HI restriction endonucleases (10 U/ $\mu$ g DNA) (Boehringer Mannheim Biochemicals, Indianapolis, IN) and Southern blotted to detect polymorphisms in the PGK and HPRT genes, respectively. For the PGK locus, DNA from heterozygous females contains two alleles at 5 and $12 \mathrm{~kb}$. For the HPRT gene, the alleles are 12 and 24 kb long. After heterozygous females were identified, genomic DNA was purified from frozen adenomas from these patients for clonal analysis $(20,21)$.

Clonal analysis: the PGK gene. 15 ug samples of leukocyte and pituitary tumor genomic DNA were restricted with $150 \mathrm{U}$ of Bst XI (New England Biolabs, Beverly, MA) and 150 U Pst I (Boehringer Mannheim Biochemicals) using standard conditions. These restriction endonucleases detect an RFLP that results in fragments 1.05 and 0.90 kb long. One-half of each DNA sample was incubated with $70 \mathrm{U}$ of methylation-sensitive restriction enzyme, Hpa II (Boehringer Mannheim Biochemicals) to digest unmethylated PGK alleles. Hpa II(+) and Hpa II(-) DNA samples from leukocyte and tumor cells were size fractionated on Tris-Acetate-EDTA (TAE)/1.5\% agarose gels.

Clonal analysis: the HPRT gene. $15 \mu \mathrm{g}$ of leukocyte and pituitary tumor genomic DNA were restricted with $150 \mathrm{U}$ of Pvu II and Bam HI (Boehringer Mannheim .Biochemicals) using standard conditions. These restriction endonucleases detect an RFLP that results in fragments 18 and $10 \mathrm{~kb}$ long. One-half of each DNA sample was incubated with $70 \mathrm{U}$ of Hpa II (Boehringer Mannheim Biochemicals) to digest unmethylated HPRT alleles. Hpa II(+) and Hpa II(-) DNA samples from leukocyte and tumor were size fractionated on TAE/1.0\% agarose gels.

Hybridization conditions and probes. TAE/agarose gels were capillary blotted onto Optibind membranes (Schleicher \& Schuell, Inc., Keene, NH) under standard conditions (24). ${ }^{32} \mathrm{P}$-DNA probes were labeled to specific activities of $0.5-1.0 \times 10^{9} \mathrm{cpm} / \mu \mathrm{g}$ by the randomprime method (25). DNA probes for the HPRT gene (HPRT-800) and the PGK gene (pSP/PGK), as well as detailed hybridization conditions, are described previously $(22,23,26,27)$. A scanning densitometer (LKB Instruments, Inc., Gaithersburg, MD) was used to quantitate autoradiographic signals.

\section{Results}

Clonal analysis, which examines $\mathrm{X}$-inactivation patterns in human tumors, relies on several biological properties of Lyonization (28). In females, inactivation of either the maternal or paternal X-chromosome is a random, balanced process which takes place early in embryogenesis. Thereafter, progeny cells retain the $\mathrm{X}$-inactivation pattern of their progenitor cell. Activation of many genes on the $\mathrm{X}$-chromosome is accompanied by changes in methylation patterns of cytosine nucleotides, which are then transmitted in a highly stable manner to progeny cells (29).

DNA restriction endonucleases are useful in distinguishing maternal and paternal X-chromosomes by revealing RFLPs within X-chromosome genes. Two X-linked loci, the PGK and HPRT genes, have RFLPs with polymorphic rates of 27 and $31 \%$, respectively (23). Approximately $50 \%$ of human females are heterozygous for one or both RFLPs, and are therefore appropriate for X-linked clonality studies. Another methylation-sensitive restriction enzyme, $\mathrm{Hpa}$ II, is used to indicate whether genomic DNA fragments originate from an active or inactive X-chromosome (30). The relative proportion of active maternal and paternal X-linked alleles is determined by DNA hybridization and autoradiography. Cells of a monoclonal origin have an identical $\mathrm{X}$-inactivation pattern, resulting in only one band present in Hpa II(+) lanes. In polyclonal tissues with random and balanced $\mathrm{X}$-inactivation patterns, maternal and paternal alleles are represented equally in $\mathrm{Hpa} \mathrm{II}(+)$ lanes, producing two bands that are reduced in intensity.

Blood leukocyte DNA from 14 females undergoing transsphenoidal surgery for removal of nonfunctioning pituitary tumors were screened for RFLPs at the PGK and HPRT loci Three females $(21 \%)$ were heterozygous at the PGK locus (patients 1,2 , and 6 ), and $5(36 \%)$ at the HPRT locus (patients 1-5). In all, six females (43\%) were appropriate for RFLP analysis. We extracted genomic DNA from their pituitary tumors, and compared X-inactivation patterns of blood leukocyte and tumor DNA.

Patients undergoing transsphenoidal surgery who were included in clonal analysis ranged in age from 32 to 65 , with a median age of 55 (see Table I). All patients presented with visual field abnormalities due to pituitary macroadenomas with extrasellar extension as assessed by computer tomography or magnetic resonance imaging. Serum levels of growth hormone and/or somatomedin C, thyroid-stimulating hormone (TSH), and thyroxine were normal in all patients. Serum levels of intact gonadotropins were inappropriately low for menopause in patients 1,2 , and 5 , while patients 3,4 , and 6 had serum levels consistent with their menstrual status (see Table I). Immunocytochemistry was performed on pituitary tumor tissue using specific antibodies for gonadotropin subunits, prolactin, and TSH-beta subunit (8). Positive immunostaining for one or more gonadotropin subunit was found in all tumors (Table II). These results did not correlate with serum alpha subunit or gonadotropin levels (Table I). None of the tumors stained positively for prolactin or TSH-beta subunit. Thus, these cases exhibited typical clinical features of nonfunctioning pituitary tumors.

Fig. 1 shows Southern blot data of RFLP analyses of the HPRT locus in blood leukocyte (used as a polyclonal control tissue) and pituitary tumor DNA from five heterozygous female patients. In polyclonal tissues with random and balanced $\mathrm{X}$-inactivation patterns, maternal and paternal alleles are rep-

Table I. Preoperative Serum Levels

\begin{tabular}{|c|c|c|c|c|c|}
\hline No. & Age & PRL & LH & FSH & $\alpha$ \\
\hline & & & IU/liter & & $n g / m l$ \\
\hline 1 & 65 & 16 & 9 & 12 & 0.6 \\
\hline 2 & 64 & 40 & 2 & 9 & 0.4 \\
\hline 3 & 57 & 25 & 44 & 95 & 1.2 \\
\hline 4 & 41 & 13 & 7 & 12 & 0.5 \\
\hline 5 & 70 & 68 & 3 & 9 & 0.9 \\
\hline 6 & 32 & 58 & 1 & 3 & 0.6 \\
\hline $\begin{array}{r}\text { Nor } \\
(p\end{array}$ & pausal) & $0-15$ & $20-187$ & $5.0-41$ & $0.5-2.5$ \\
\hline \multicolumn{6}{|c|}{ Normal } \\
\hline
\end{tabular}

PRL, prolactin; LH, intact luteinizing hormone; FSH, intact folliclestimulating hormone; and $\alpha$, alpha subunit. 

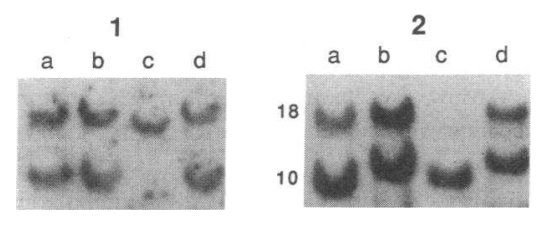

4

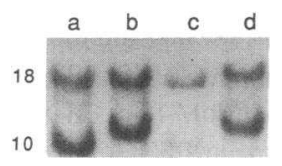

Figure 1. Clonal analysis of pituitary tumors at the HPRT gene. Southern blots of DNA from blood leukocytes (lanes $a$ and $b$ ) and nonfunctioning pituitary tumors (lanes $c$ and $d$ ) from patients 1-5. Lanes $a$ and $c, 7.5 \mu \mathrm{g}$ of leukocyte genomic DNA restricted with Bam H1, Pvu II, and Hpa II; lanes $b$ and $d, 7.5 \mu \mathrm{g}$ of leukocyte genomic DNA restricted with Bam $\mathrm{H} 1$ and Pvu II alone. 18 and 10 are the lengths in kilobases of the two HPRT alleles.

resented equally in $\mathrm{Hpa} \mathrm{II}(+)$ lanes, producing two bands. Lanes $a$ and $b$ in Fig. 1 show a random, balanced polyclonal pattern of $\mathrm{X}$-inactivation in blood leukocytes from these female patients, in that both HPRT bands are reduced in intensity in roughly equal proportions after $\mathrm{Hpa}$ II digestion (lane a). In order to quantitate this reduction, densitometry was performed on autoradiographs to determine the percentage loss of each HPRT allele in Hpa II lanes (17). Cleavage ratios were then determined by dividing the greater remaining intensity by the lesser. Using this method, cleavage ratios of polyclonal leukocyte DNA should approach 1.0, a value indicating balanced X-inactivation. Blood leukocyte cleavage ratios for these five female patients at the HPRT gene were 1.1, 1.3, 1.1, 1.3 , and 2.3, representing the nonpreferential cleavage of the two X-chromosomes by Hpa II.

In contrast, cleavage ratios of pituitary adenoma DNA from each of these five females greatly exceeded 1.0. The cleavage ratios of HPRT alleles from these tumors were $68,70,61$, 29 , and 14 in patients $1-5$, respectively. Fig. 1 shows the loss of a single HPRT allele in Hpa II lanes (lanes $c$ ). Cells of a monoclonal origin have an identical $\mathrm{X}$-inactivation pattern, resulting in only one band present in $\mathrm{Hpa} \mathrm{II(+)} \mathrm{lanes.} \mathrm{The} \mathrm{clear}$ preference of $\mathrm{Hpa}$ II for a single $\mathrm{X}$-chromosome in adenoma DNA indicates the monoclonal origins of these five tumors.

Fig. 2 shows Southern blot data of RFLP analyses of the PGK locus in blood leukocyte and pituitary tumor DNA from
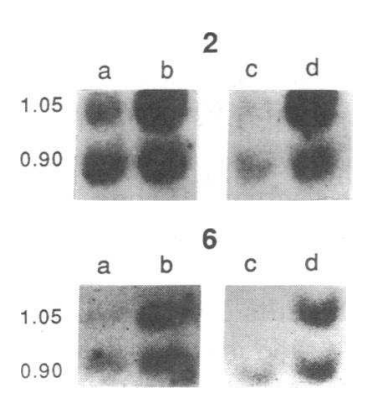

Figure 2. Clonal analysis of pituitary tumors at the PGK gene. Southern blots of DNA from blood leukocytes (lanes $a$ and $b$ ) and nonfunctioning pituitary tumors (lanes $c$ and $d$ ) from patients 2 and 6. Lanes $a$ and $c, 7.5$ $\mu \mathrm{g}$ of leukocyte genomic DNA restricted with Bst X1, Pst I, and Hpa II; lanes $b$ and $d, 7.5 \mu \mathrm{g}$ of leukocyte genomic DNA restricted with Bst X1 and Pst $I$ alone. 1.05 and 0.90 are the lengths in kilobases of the two PGK alleles.
Table II. Immunocytochemical Staining of Pituitary Tumors

\begin{tabular}{lccc}
\hline No. & LH $\beta$ & FSH $\beta$ & $\alpha$ \\
\hline 1 & + & + & - \\
2 & - & +++ & + \\
3 & - & ++ & + \\
4 & - & - & + \\
5 & - & - & ++ \\
6 & + & - & +++ \\
\hline
\end{tabular}

$\mathrm{LB} \beta$, luteinizing hormone beta subunit; $\mathrm{FSH} \beta$, follicle-stimulating hormone beta subunit; $\alpha$, alpha subunit.

- , no positive staining cells;,$+<5 \%$ positive staining cells; ++

$5-25 \%$ positive staining cells;,$+++>25 \%$ positive staining cells.

two heterozygous female patients. Patient 2 was heterozygous at both the HPRT and PGK genes, allowing for clonal analysis at each locus. In this patient, cleavage ratios for control blood leukocyte and tumor DNA at the PGK gene were 1.5 and 35, respectively. Thus, we were able to demonstrate monoclonality in tumor DNA from patient 2 using two separate sites on the X-chromosome. Blood leukocyte DNA from patient 6 appeared to be hypomethylated at the $1.05-\mathrm{kb}$ allele, which was reduced in the Hpa II lane (lane $a$ ) by $81 \%$. The $0.90-\mathrm{kb}$ band was reduced by $53 \%$, an expected result. This hypomethylation of the 1.05-kb band resulted in an increased cleavage ratio of 2.5. However, pituitary tumor DNA showed a monoclonal pattern of Hpa II digestion, with a cleavage ratio of 31 . Hypomethylation of inactive PGK genes in this patient's leukocytes did not preclude clonal analysis, given that the cleavage ratio of PGK alleles was substantially higher in pituitary tumor DNA.

\section{Discussion}

Our findings indicate that nonfunctioning pituitary neoplasms are monoclonal in origin, suggesting that somatic mutation plays an important role in the neoplastic transformation of this type of pituitary tumor. Clonal analysis allows one to make the important distinction between a polyclonal proliferation in response to a stimulatory factor versus a monoclonal expansion of a genetically aberrant cell.

Very few benign neoplasms, including endocrine tumors, have been investigated for clonal analysis. For example, Arnold et al. demonstrated that sporadic parathyroid adenomas arise from a single progenitor cell (17). Conversely, X-inactivation studies at the HPRT and PGK genes have shown that nonfamilial primary parathyroid hyperplasia appears to be polyclonal in origin, suggesting that this type of growth may be initiated in response to circulating factors (17).

Familial multiple endocrine neoplasia type 1 (MEN-1) is a hereditable disorder that leads to hyperfunction of pancreatic islets, anterior pituitary, and multiple parathyroid glands (31). Genetic linkage analysis has mapped the MEN-1 locus to chromosome 11 (32). Allelic changes along chromosome 11, particularly 11q13, have been demonstrated in parathyroid tumors and insulinomas associated with MEN-1 $(32,33,34)$. These studies have implicated somatic loss of the MEN-1 locus, a putative tumor suppressor gene, as an important fac- 
tor in this inherited predisposition for neoplasia of endocrine tissues. Moreover, they indicate that at least some "hyperplastic" parathyroid tumors in MEN-1 patients are actually monoclonal, and tumor growth could be initiated by allelic loss of the MEN-1 gene. Our finding that nonfunctioning pituitary tumors are monoclonal suggests that a search for similar allelic changes may help elucidate the pathogenesis of such tumors.

It has long been speculated that hypothalamic dysregulation may be an underlying cause of pituitary tumors (13), however these data suggest that hypothalamic factors alone are not sufficient for tumorigenesis. Perturbations of the hypothalamic-pituitary-gonadal axis, such as long-standing hypogonadism, have also been suggested to cause pituitary hyperplasia of gonadotroph cells (35). However, the monoclonal origins of these nonfunctioning tumors indicate that such is not the case in these patients.

Our data are consistent with the hypothesis that spontaneous somatic mutation of a single anterior pituitary cell is a requisite event for the transformation of normal anterior pituitary cells into benign adenomas. The monoclonal nature of these tumors makes unlikely the possibility that circulating factors (hypothalamic or others) alone can transform pituitary cells and lead to neoplasia. Therefore, somatic mutation of pituitary cells is at least one of the necessary "hits" that invoke neoplasia; if external factors play a role, then they affect pituitary cells that have undergone somatic changes potentiating their transformation.

Furthermore, the monoclonal nature of these tumors suggests that the requisite cellular changes that invoke pituitary neoplasia occur very rarely. Well-defined genetic changes that correlate with tumorigenesis have been described in several tumor types (36). In this regard, our results demonstrating the monoclonal origin of nonfunctioning pituitary adenomas are important for future studies investigating the precise somatic changes associated with pituitary tumorigenesis.

\section{Acknowledgments}

This work was supported by National Institute of Diabetes and Digestive and Kidney Disease grants DK-40947, DK-08330, and DK-07028. Dr. Arnold is the recipient of a Junior Faculty Research Award from the American Cancer Society.

\section{References}

1. Klibanski, A. 1987. Nonsecreting pituitary tumors. Endocrinol. Metab. Clin. North Am. 16:793-803.

2. Klibanski, A., E. C. Ridgway, and N. T. Zervas. 1983. Pure alpha subunit-secreting pituitary tumors. J. Neurosurg. 59:585-89.

3. Ridgway, E. C., A. Klibanski, P. W. Ladenson, D. Clemmons, I. E. Beitins, J. W. MacArthur, M. A. Martorana, and N. T. Zervas. 1981. Pure alpha-secreting pituitary adenomas. N. Engl. J. Med. 304:1254-1259.

4. Snyder, P. J. 1985. Gonadotroph adenomas of the pituitary. Endocr. Rev. 6:552-563.

5. Arafah, B. M. 1986. Reversible hypopituitarism in patients with large nonfunctioning pituitary adenomas. J. Clin. Endocrinol. \& Metab. 62:1173-1179.

6. Jameson, J. L., A. Klibanski, P. McL. Black, N. T. Zervas, C. M. Lindell, D. W. Hsu, E. C. Ridgway, and J. F. Habener. 1987. Glycoprotein hormone genes are expressed in clinically nonfunctioning pituitary adenomas. J. Clin. Invest. 80:1472-1478.

7. Jameson, J. L., C. M. Lindell, and J. F. Habener. 1987. Gonado- tropin and thyrotropin alpha- and beta-subunit gene expression in normal and neoplastic tissues characterized using specific messenger ribonucleic acid hybridization probes. J. Clin. Endocrinol. \& Metab. 64:319-327.

8. Klibanski, A., P. J. Deutsch, J. L. Jameson, E. C. Ridgway, W. F. Crowley, D. W. Hsu, J. F. Habener, and P. McL. Black. 1987. Luteinizing hormone-secreting pituitary tumor: biosynthetic characterization and clinical studies. J. Clin. Endocrinol. \& Metab. 64:536542.

9. Klibanski, A., M. A. Shupnik, H. A. Bikkal, P. McL. Black, B. Kliman, and N. T. Zervas. 1988. Dopaminergic regulation of alphasubunit secretion and mRNA levels in alpha-secreting pituitary tumors. J. Clin. Endocrinol. \& Metab. 66:96-102.

10. Black, P. McL., D. W. Hsu, A. Klibanski, B. Kliman, J. L. Jameson, E. C. Ridgway, E. T. Hedley-White, and N. T. Zervas. 1987. Production of glycoprotein hormone subunits in clinically nonfunctioning pituitary tumors. J. Neurosurg. 66:244-250.

11. DeStephano, D. B., R. V. Lloyd, A. M. Pike, and B. S. Wilson. 1984. Pituitary adenomas: an immunohistochemical study of hormone production and chromogranin localization. Am. J. Pathol. 116:464-472.

12. Kovacs, K. 1985. Light and electron microscopic pathology of pituitary tumors: immunocytochemistry. In Secretory Tumors of the Pituitary Gland. P. McL. Black, N. T. Zervas, E. C. Ridgeway, and J. B. Martin, editors. Raven Press, Ltd., New York. 365-376.

13. Molitch, M. E. 1987. Pathogenesis of pituitary tumors. Endocrinol. Metab. Clin. North Am. 16:503-527.

14. Woodruff, M. F. A. 1988. Tumor clonality and its biological significance. Adv. Cancer Res. 50:197-229.

15. Fialkow, P. J., R. W. Sagabiel, S. M. Gartler, and D. L. Rimoin. 1971. Multiple cell origin of hereditary neurofibromas. N. Engl. J. Med. 284:298-300.

16. Gartler, S. M., L. Ziprkowski, and A. Krakowski. 1966. Glucose-6-phosphate dehydrogenase mosaicism as a tracer in the study of hereditary multiple trichoepithelioma. Am. J. Hum. Genet. 18:282287.

17. Arnold, A., C. E. Staunton, H. G. Kim, R. D. Gaz, and H. M. Kronenberg. 1988. Monoclonality and abnormal parathyroid hormone genes in parathyroid adenomas. N. Engl. J. Med. 318:658-662.

18. Fearon, E. R., P. J. Burke, C. A. Schiffer, B. A. Zehnbauer, and B. Vogelstein. 1986. Differentiation of leukemia cells to polymorphonuclear leukocytes in patients with acute nonlymphocytic leukemia. N. Engl. J. Med. 315:15-24.

19. Fearon, E. R., S. R. Hamilton, and B. Vogelstein. 1987. Clonal analysis of colorectal tumors. Science (Wash. DC). 238:193-197.

20. Gross-Bellard, M., P. Oudet, and P. Chambon. 1973. Isolation of high-molecular weight DNA from mammalian cells. Eur. J. Biochem. 36:32-38.

21. Fearon, E. R., A. P. Feinberg, S. R. Hamilton, and B. Vogelstein. 1987. Loss of genes on the short arm of chromosome 11 in bladder cancer. Nature (Lond.). 318:377-380.

22. Vogelstein, B., E. R. Fearon, S. R. Hamilton, and A. P. Feinberg. 1985. Use of restriction fragment length polymorphisms to determine the clonal origin of human tumors. Science (Wash. DC). 227:642-645.

23. Vogelstein B., E. R. Fearon, S. R. Hamilton, A. C. Preisinger, H. F. Willard, A. M. Michelson, A. D. Riggs, and S. H. Orkin. 1987. Clonal analysis using recombinant DNA probes from the X-chromosome. Cancer Res. 47:4806-4813.

24. Southern, E. M. 1975. Detection of specific sequences among DNA fragments separated by gel electrophoresis. J. Mol. Biol. 98:503-517.

25. Feinberg, A. P., and B. Vogelstein. 1983. A technique for radiolabeling DNA restriction endonuclease fragments to high specific activity. Anal. Biochem. 132:6-13.

26. Jolly, D. J., A. C. Esty, H. U. Bernard, and T. Friedmann. 1982. 
Isolation of a genomic clone partially encoding human hypoxanthine phosphoribosyltransferase. Proc. Natl. Acad. Sci. USA. 79:5038-5041.

27. Keith, D. H., J. Singer-Sam, and A. D. Riggs. 1986. Active $\mathrm{X}$-chromosome DNA is unmethylated at eight CCGG sites clustered in a guanine-plus cytosine-rich island at the $5^{\prime}$ end of the gene for phosphoglycerate kinase. Mol. Cell. Biol. 6:4122-4125.

28. Lyon, M. F. 1961. Gene action on the X-chromosome of the mouse (mus musculus L.). Nature (Lond.). 190:372-373.

29. Gartler, S. M., and A. C. Riggs. 1983. Mammalian X-chromosome inactivation. Annu. Rev. Genet. 17:155-190.

30. Yen, P. H., P. Patel, A. C. Cinault, T. Mohandas, and L. J. Shapiro. 1984. Differential methylation of hypoxanthine phosphoribosyltransferase gene on active and inactive human $\mathrm{X}$ chromosomes. Proc. Natl. Acad. Sci. USA. 81:1759-1763.

31. Brandi, M. L., S. J. Marx, G. D. Aurbach, and L. A. Fitzpatrick. 1988. Familial multiple endocrine neoplasia type I: a new look at pathophysiology. Endocr. Rev. 8:341-405.

32. Larrson, C., B. Skogseid, K. Oberg, Y. Nakamura, and M.
Nordenskjold. 1988. Multiple endocrine neoplasia type I gene maps to chromosome 11 and is lost in insulinoma. Nature (Lond.). 332:85-87.

33. Thakker, R. V., P. Bouloux, C. Wooding, K. Chotai, P. M. Broad, N. K. Spurr, G. M. Besser, and J. L. H. O'Riordan. 1989. Association of parathyroid tumors in multiple endocrine neoplasia type 1 with loss of alleles on chromosome 11. N. Engl. J. Med. 321:218-224.

34. Friedman, E., K. Sakaguchi, A. E. Bale, A. Falchetti, E. Streeten, M. B. Zimering, L. S. Weinstein, W. O. McBride, Y. Nakamura, M.-L. Brandi, J. A. Norton, G. D. Auerbach, A. M. Speigel, and S. J. Marx. 1989. Clonality of parathyroid tumors in familial multiple endocrine neoplasia type 1. New Engl. J. Med. 321:213-218.

35. Reichlin, S. 1984. Neuroendocrine control of thyrotropin and gonadotropin secretion. In Secretory Tumors of the Pituitary Gland. P. McL. Black, N. T. Zervas, E. C. Ridgway, and J. B. Martin, editors. Raven Press, Ltd. New York. 309-325.

36. Bishop, J. M. 1987. The molecular genetics of cancer. Science (Wash. DC). 235:305-311. 